\title{
A social work study on parents' income and personal characteristics and child abuse: A case study of city of Esfahan
}

\author{
Mohammad Reza Iravani $^{\mathrm{a}^{*}}$, Shahram Basity ${ }^{\mathrm{b}}$, Faezeh Taghipour ${ }^{\mathrm{c}}$, AllahyarArabmomeni ${ }^{\mathrm{d}}$ and \\ HajarJannesari ${ }^{\mathrm{e}}$
}

\author{
${ }^{a}$ Assistant Professor, Department of Social Work, Islamic Azad University Khomeinishahr Branch, Daneshjou Blvd, Iran \\ ${ }^{b} \mathrm{PhD}$, Department of Social Science, Payame Noor University/PO BOX 19395-3697 Tehran, Iran \\ ${ }^{c}$ Assistant Professor, Department of Cultural Management Khorasgan (Isfahan) Branch, Islamic Azad University, Isfahan, Iran \\ ${ }^{d}$ Department of Human Science of Islamic Azad University Khomeinishahr Branch, Isfahan, Iran \\ cMS Student, Counseling Department, Islamic Azad University of Khomeinishahr, Khomeinishahr Branch, Daneshjou Blvd, Iran
}

\section{H R O N I C L E}

\section{Article history:}

Received October 9, 2012

Received in revised format

29 November 2012

Accepted 27 December 2012

Available online

January 42013

Keywords:

Child abuse

Drug addiction

Esfahan

\begin{abstract}
A B S T R A C T
Child abuse is one of the most important issues in any society and any action to detect influencing factors could help take possible actions on its prevention. In this paper, we present an empirical study to find the impact of family income, occupation, size, age, education and drug addiction on growth of child abuse. The study uses a sample of 450 female students who were enrolled on guided schools in city of Esfahan, Iran. The study chooses 5 classes and in each school and 10 students are randomly selected. A questionnaire is designed and distributed among the sample people, which is categorized in four groups of physical, sexual, emotional and neglect child abuse. The results are analyzed using different tests including Pearson correlation test, Chi-Square, etc. to test different hypotheses. The results of our survey indicate that there are some meaningful relationships between different family characteristics including age, occupation, family size, educational background, and drug-addiction and child abuse. However, our survey does not provide any evidence to believe there is any relationship between home status and child abuse risk.
\end{abstract}

\section{Introduction}

Today, despite the cultural and scientific advances, the number of reports of injuries and social damage that comes to children is increasing. This has led many countries and international organizations to reduce possible risks to children's lives (Lalor, 2004). Historically, children have been considered as the most vulnerable groups of society and they have always been subject to numerous risks. Physical and emotional child abuse is one of the most common forms of hurting children, which must be stopped through possible actions. Surveys and studies have shown that parents who commit such acts are often of low levels of literacy and awareness and if there are some

*Corresponding author. Tel: +989130758065

E-mail addresses: iravani@iaukhsh.ac.ir (M. R. Iravani) 
changes on parents' believes, we may hope there would be a reduction on child abuse. The Iranian maintains young people and there is more attention of bottom of the pyramid population ages specially people aged less than 18 years. Child abuse has been a major in other societies including developed or developing countries.

Leander (2010) studied 27 sexually abused children's reports about abuse given in the context of police interviews. She analyzed the interviews with the children based on the type of information reported, and the frequency of denial and avoidance. The study concluded that sexually abused children could be highly resistant to reporting about the abuse in police interviews, and that two or three interviews would be needed to enable children to give complete and informative reports.

de Paúl et al. (1995) gathered information on childhood physical and sexual abuse and compared abuse rates with a similar study performed in the United States. They investigated the relationships between childhood physical and sexual abuse, childhood social support, and abuse potential in the Basque sample and reported that despite the fact that overall rates of physically abusive behaviors were similar in the Basque and US samples, the rates of physical abuse sequelae were lower in the Basque sample. Besides, the sexual abuse rates for Basque males were more than double the rates found for US males. A childhood history of physical and sexual abuse were directly associated with child abuse potential. They also reported an interaction between a childhood history of physical abuse and father support.

Tajima (2000) investigated the relative importance of wife abuse for physical child abuse, verbal child abuse and physical punishment. The study revealed the relative importance of wife abuse compared with blocks of parent, child, and family characteristics. The study revealed child, blocks of parent, and family characteristics were more important predictors of violence towards children than was wife abuse. Tutty (1994) investigated developmental issues in young children's learning of sexual abuse prevention concepts. Swanston et al. (2002) determined the incidence of re-abuse in children known to have been sexually abused and detected important factors, which increase the risk of reabuse. They reported that intervention in child sexual abuse needed to consider a range of risk factors related to re-abuse.

O'Toole et al. (1999) determined the impact of organizational setting on recognition and reporting of child abuse and reported that teachers responses to child abuse were relatively unbiased by either the extraneous characteristics of the perpetrator or victim or the school setting. Rudin et al. (1995) investigated different characteristics of child sexual abuse victims through a comparison of 87 victims of lone female perpetrators to 93 victims of lone male perpetrators based on their age, gender, and relationship of perpetrator to the victim.

Milner et al. (2010) investigated whether trauma symptoms could act as mediator on the relationship between a childhood history of child physical abuse (CPA) and adult CPA risk, and whether any such mediation was the same for women and men. They reported that there was a strong relationship between a childhood history of CPA and adult CPA risk. This relationship was significant even after controlling for demographic variables and childhood exposure to other forms of violence.

Hemmati Noedoust Gilani et al. (2012) performed a survey on some Iranian families and concluded that parents could substantially contribute to schools to increase their capabilities through sharing their knowledge and expertise. However, school officials do not strongly believe that the presence of parents could solve any problem and they mostly disagreed to share their duties with parents. Iravani et al. (2012) investigated women's position on domestic violence by designing a questionnaire and distributing it among 880 people who were residences of city of Esfahan, Iran. The result of the survey confirmed that Iranian women experienced various types of violence in their lives. 
In this paper, we present an empirical study to find the impact of family income, occupation, size, age, education and drug addiction on growth of child abuse. The organization of the paper first presents details of the survey in section 2 and section 3 presents the results of our investigation. The paper ends with concluding remarks to summarize the contribution of the paper.

\section{The proposed study}

The proposed study of this paper is to find the effects of family income, occupation, size, age, education and drug addiction on growth of child abuse. The study uses a sample of 450 female students who were enrolled on guided schools in city of Esfahan, Iran. The study chooses 5 classes and in each school and 10 students are randomly selected from nine different schools. A questionnaire is designed and distributed among the sample people, which is categorized in four groups of physical, sexual, emotional and neglect child abuse. The results are analyzed using different tests including Pearson correlation test, Chi-Square, etc. to test different hypotheses. Fig. 1 shows characteristics of the participants in terms of their age.

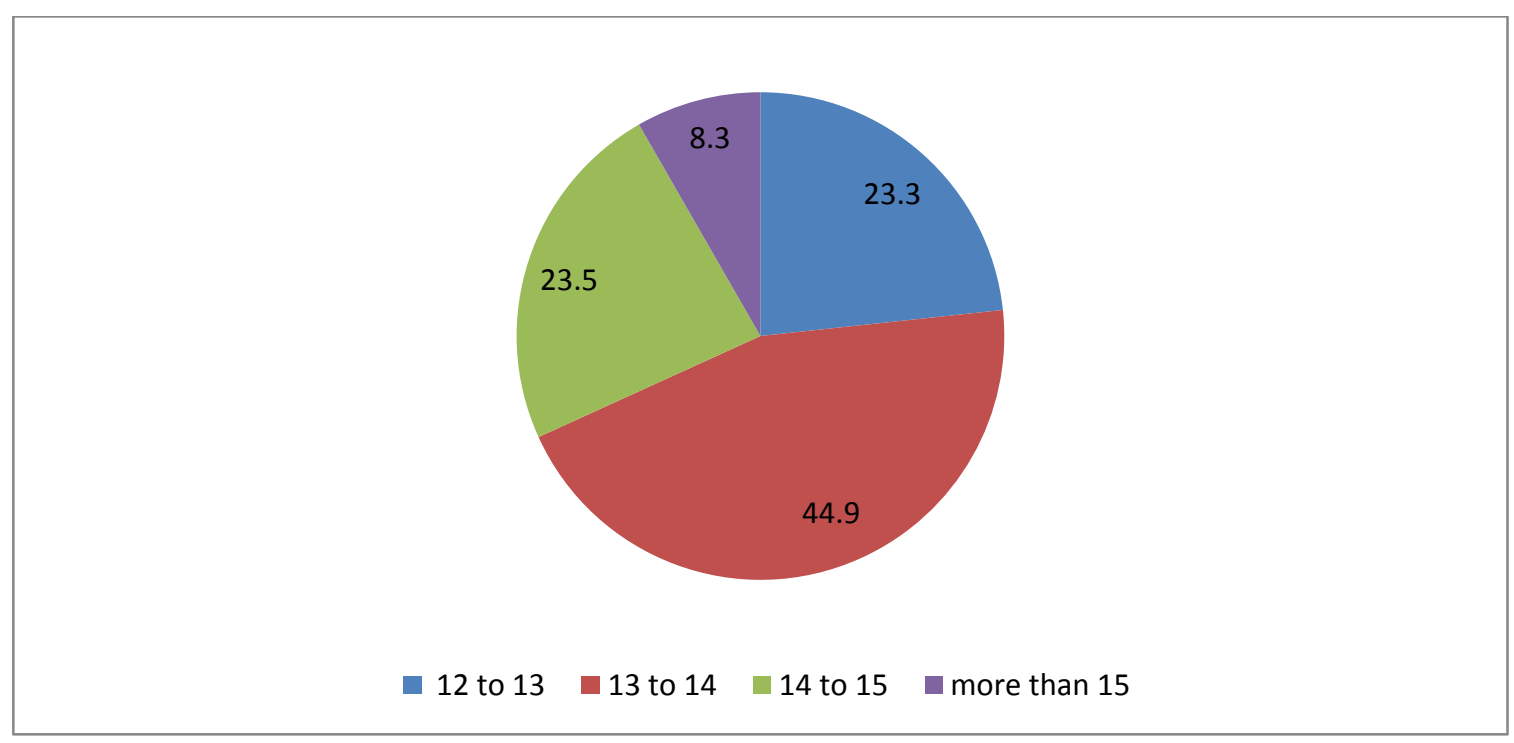

Fig. 1. Personal characteristics of participants in terms of their age

The proposed study of this paper considers the following hypotheses,

1. There is a relationship between parents' age and risk of child abuse.

2. There is a relationship between parents' family size and risk of child abuse.

3. There is a relationship between parents' income and risk of child abuse.

4. There is a relationship between parents' educational background and risk of child abuse.

5. There is a relationship between parents' occupations and risk of child abuse.

6. There is a relationship between parents' home status and risk of child abuse.

7. There is a relationship between parents' drug-addiction and child abuse.

The proposed study of this paper uses pairwise t-student test to verify the hypotheses. 


\section{The results}

In this part of the survey, we examine the relationship between different family characteristics and child abuse risk.

\subsection{The first hypothesis: The relationship between age and child abuse}

The first hypothesis of the survey investigates whether there is any relationship between age and child abuse. We have divided the sample test into two equal groups and Table 1 shows details of our findings,

\section{Table 1}

Details of testing the first hypothesis on relationship between age and risk of child abuse

\begin{tabular}{ccccc}
\hline Child abuse & Number & Standard deviation & Mean standard error & Sig. \\
\hline Age Child abuse exists & 225 & .965 & .117 & 0.000 \\
Child abuse does not exist & 225 & .528 & .0626 & \\
\hline
\end{tabular}

As we can observe from the results of Table 1, there is a meaningful relationship between age and child abuse.

\subsection{The second hypothesis: The relationship between family size and child abuse}

The second hypothesis of the survey investigates whether there is any relationship between family size and child abuse. Table 2 demonstrates details of testing the second hypothesis,

Table 2

Details of testing the second hypothesis on relationship between family size and risk of child abuse

\begin{tabular}{|c|c|c|c|c|c|}
\hline & Child abuse & Number & Standard deviation & Mean standard error & Sig. \\
\hline Family & Child abuse exists & 225 & .968 & .116 & 0.000 \\
\hline size & Child abuse does not exist & 225 & .525 & .0625 & \\
\hline
\end{tabular}

As we can observe from the results of Table 2, there is a meaningful relationship between family size and child abuse.

\subsection{The third hypothesis: The relationship between family income and child abuse}

The third hypothesis of the survey investigates whether there is any relationship between family income and child abuse. Table 3 demonstrates details of testing the third hypothesis,

\section{Table 2}

Details of testing the third hypothesis on relationship between family income and risk of child abuse

\begin{tabular}{lccccc}
\hline \multicolumn{1}{c}{ Child abuse } & Number & Mean & $\begin{array}{c}\text { Standard } \\
\text { deviation }\end{array}$ & $\begin{array}{c}\text { Mean standard } \\
\text { error }\end{array}$ & Sig. \\
\hline $\begin{array}{l}\text { Family } \\
\text { income }\end{array}$ & 225 & 1.85 & .68 & .073 & 0.000 \\
\hline
\end{tabular}

As we can observe from the results of Table 3, there is a meaningful relationship between family income and child abuse. 
Our survey has also concluded that there were meaningful relationships between parents' educational background, parents' occupations and their drug-addiction with risk of child abuse. However, there was no evidence to believe there is any relationship between home status and risk of child abuse. Since family size plays an important role in increasing or decreasing risk of child abuse, there must be some informative guidelines to have a better control on risk of child abuse. Marriage needs to be performed more carefully and people need to think that many forced marriage, early age marriage, etc. could increase the chance of child abuse. In fact, when some teenagers get married, they may not know much about how to raise their children and this could create serious problems. Public and private agencies should devote their efforts to the children who are in domestic violence trying to protect them against any possible further child abuse.

\section{Conclusion}

In this paper, we have presented an empirical investigation to find the impact of family income, occupation, size, age, education and drug addiction on growth of child abuse. The study has used a sample of 450 female students who were enrolled on guided schools in city of Esfahan, Iran. The study chose 5 classes and in each school and 10 students have been randomly selected. A questionnaire was designed and distributed among the sample people categorized in four groups of physical, sexual, emotional and neglect child abuse. The results have been analyzed using different tests including Pearson correlation test, Chi-Square, etc. to test various hypotheses. The results of our survey have indicated that there were some meaningful relationships between different family characteristics including age, occupation, family size, educational background, and drug-addiction and child abuse. However, our survey does not provide any evidence to believe there is any relationship between home status and child abuse risk.

\section{Acknowledgment}

The authors would like to thank the officials of all guided schools for their cooperation in accomplishing this survey.

\section{References}

Hemmati Noedoust Gilani, N., Sadeghizadeh, S., Iravani, M.R., \& Sadeghi Zadeh, M. (2012). A survey on the effects of parents' involvement on schoolchildren educational background. Management Science Letters, 2(5), 1661-1668.

de Paúl, J., Milner, J.S., \& Múgica, P. (1995). Childhood maltreatment, childhood social support, and child abuse potential in a Basque sample. Child Abuse \& Neglect, 19(8), 907-920.

Iravani, M.R., Sedrpoushan, N., \& Afghami Ardakani, I. (2012). A social work study on violence against women. Management Science Letters, 2(4), 1409-1416.

Lalor, K. (2004). Child sexual abuse in sub-Saharan Africa: a literature review. Child Abuse \& Neglect, 28(4), 439-460

Leander, L. (2010). Police interviews with child sexual abuse victims: Patterns of reporting, avoidance and denial. Child Abuse \& Neglect, 34(3), 192-205.

Milner, J.S., Thomsen, C.J., Crouch, J.L., Rabenhorst, M.M., Martens, P.M., Dyslin, C.W., Guimond, J.M., Stander, V.A., \& Merrill, L.L. (2010). Do trauma symptoms mediate the relationship between childhood physical abuse and adult child abuse risk? Child Abuse \& Neglect, 34(5),332344.

O’Toole, R., Webster, S.W., O’Toole, A.W., \& Lucal, B. (1999). Teachers' recognition and reporting of child abuse: a factorial survey. Child Abuse \& Neglect, 23(11), 1083-1101.

Rudin, M.M., Zalewski, C., \& Bodmer-Turner, J. (1995). Characteristics of child sexual abuse victims according to perpetrator gender. Child Abuse \& Neglect, 19(8), 963-973 
Tajima, E.A. (2000). The relative importance of wife abuse as a risk factor for violence against children. Child Abuse \& Neglect, 24(11), 1383-1398.

Tutty, L. M. (1994). Developmental issues in young children's learning of sexual abuse prevention concepts. Child Abuse \& Neglect, 18(2), 179-192.

Swanston, H.Y., Parkinson, P.N., Oates, R.K., O’Toole, B.I., Plunkett, A.M., \& Shrimpton, S. (2002). Further abuse of sexually abused children. Child Abuse \& Neglect, 26(2), 115-127. 